\title{
Risk of Coronary Heart Disease in People with Chronic Obstructive Pulmonary Disease: A Meta-Analysis
}

Jia-Jie Wang (D)

Medical College, Soochow University, Suzhou, Jiangsu Province, People's

Republic of China
Correspondence: Jia-jie Wang Medical College, Soochow University, No. 199 Ren Ai Road, Industrial Park, Suzhou, Jiangsu Province, People's

Republic of China

$\mathrm{Tel}+86$ I89608I077|

Email364352199@qq.com
Background: Patients with chronic obstructive pulmonary disease complicated with coronary heart disease are a major public health problem, but it has not been widely accepted by the public or health professionals, the purpose of this study is to conduct a meta-analysis of the literature reports on the risk of coronary heart disease in patients with chronic obstructive pulmonary disease.

Methods: Data sources are PubMed and Web of Science searched up to August 2021. Design is meta-analysis.

Results: Literature searches yielded 8877 records, meta-analysis showed that the risk of coronary heart disease in chronic obstructive pulmonary disease patients was 1.24 times higher than that in non-chronic obstructive pulmonary disease patients $(\mathrm{HR}=1.24,95 \% \mathrm{CL}$ 1.16-1.32).

Conclusion: The findings suggest that patients with chronic obstructive pulmonary disease are at a higher risk of developing coronary heart disease than non-chronic obstructive pulmonary disease patients.

Keywords: meta-analytic methods, coronary heart disease risk, chronic obstructive pulmonary disease, COPD

\section{Introduction}

COPD is characterized by chronic pulmonary inflammation, which leads to progressive and irreversible airflow obstruction, and periodic acute exacerbations deteriorate and aggravate. ${ }^{1}$ The global prevalence rate of COPD was 251 million in 2016 and 3.17 million people died in $2015 .^{2}$ CHD and COPD are among of the three main causes of death in the world. ${ }^{3,4}$ COPD increases the risk of CHD due to chronic systemic/local inflammation. ${ }^{1,3-6}$ And traditional cardiovascular risk factors such as smoking, hypertension, hyperlipidemia are highly prevalent in patients with COPD, they could contribute to COPD progression. ${ }^{7}$ Epidemiological studies have also shown that the incidence of cardiovascular death in patients with COPD is high. ${ }^{5}$ Patients with COPD complicated with CHD are a major public health problem.

The 2016 European guidelines for Cardiovascular Disease Prevention published by European Society of Cardiology show that the main risk factors for CHD are age, sex, Family history/genetics, smoking, living habits, blood pressure, blood lipid level and so on, excluding COPD. ${ }^{8}$ Although it has been previously reported that COPD is closely related to the increase in CHD, it has not been widely accepted by the public or health professionals. 
Therefore, the purpose of this study is to conduct a meta-analysis of the literature reports on the risk of CHD in patients with COPD. At present, there is no literature report on meta-analysis using cohort study. Compared with the meta-analysis of previous casecontrol studies, the latter did not consider the time experienced and may draw inappropriate conclusions, and the former has a stronger causality and can better prove that COPD is a risk factor for CHD.

\section{Methods}

\section{Literature Search}

A systematic literature search was all literature at PubMed and Web of Science before August 2021, a meta-analysis was performed using a predefined search strategy to investigate the association between COPD and CHD prevalence in a cohort study, the specific search term is (((COPD) AND (coronary disease OR coronary heart disease OR chronic coronary artery disease OR acute coronary syndrome OR arteriosclerotic cardiovascular disease)) AND Hazard Ratio). Titles and abstracts, where available, were screened for possible inclusion and then full-text versions of potential inclusion studies were obtained for further screening, done independently by the author. The characteristics and results of the study were tabulated and compared.

\section{Inclusion and Exclusion Criteria}

I included five cohort studies that reported Hazard Ratio and corresponding $95 \%$ confidence intervals based on multifactorial adjustments in the Cox model. The subjects were the general population, the exposure group was diagnosed with COPD, the non-exposure group was not diagnosed with COPD, and the result was CHD.

\section{Risk of Bias Assessment}

I use PRISMA to evaluate.

\section{Data Analysis}

In this study, fixed effect model meta-analysis was used to merge the results, and $\mathrm{O}$ - E and Variance was used to deal with HR values, all of which were carried out on Review Manager 5.4.1. I used the $\mathrm{P}$ value of $\mathrm{Q}$ and $\mathrm{I}^{2}$ to test the heterogeneity, such as $\mathrm{I}^{2}$ more than $70 \%$ or $\mathrm{P}<0.05$, then considered that the statistical heterogeneity was too large, and the sensitivity analysis was used for further treatment. Evaluation of publication bias by funnel diagram.

\section{Results}

Literature searches yielded 8877 records. After title and abstract screening, 24 records were selected for full-text assessment, which resulted in the inclusion of 5 studies. The inclusion and exclusion process is summarized in Figure 1. The total number of patients is 26,603. The meta-analyses were based on 5 separately conducted cohort studies, ${ }^{9-13}$ the characteristics and results of included study are shown in Table 1.

One of the five studies were excluded and will be discussed later. Of the four studies included, three found that COPD patients had a higher risk of developing CHD than non-COPD patients, and all of the three studies resulted in HR adjusted for age, sex, co-illness or confounding factors, while one adjusted only for age and sex. The meta-analysis of the four studies included showed that the risk of CHD in COPD patients was 1.24 times higher than that in non-COPD patients (HR $=1.24,95 \%$ CL $1.16-$ 1.32) (Figure 2).

\section{Discussion}

Because only in the study of Ingebrigtsen, the situation of COPD was graded, while other literatures only pointed out that they had COPD, and because of the insufficient number of literatures, it was impossible to carry out subgroup analysis. Therefore, the study of Ingebrigtsen was divided into Ingebrigtsen stage 1+2 2020 and Ingebrigtsen stage3 +4 2020 according to the original text.

In evaluating the published bias of six studies with funnel maps, Ingebrigtsen stage $3+42020$ was located outside the dotted line of funnel maps, possibly because the subjects included in the study had a higher burden of disease and were more likely to develop CHD than other studies, so Ingebrigtsen stage $3+42020$ was excluded.

When the other five studies were tested for heterogeneity, Q was $P<0.05, \mathrm{I}^{2}$ was $79 \%, \mathrm{HR}=1.34(95 \% \mathrm{CL}$ $1.27-1.41)$, heterogeneity was too large, sensitivity analysis was carried out, excluding Ingebrigtsen stage $1+22020$, $P>0.05, \mathrm{I}^{2}=52 \%$, there was no heterogeneity and $\mathrm{HR}=1.24 \quad(95 \% \quad \mathrm{CL}$ 1.16-1.32). Ingebrigtsen stage $1+2$ 2020 reversed the heterogeneity results, but did not change the relationship between COPD patients and the risk of CHD. The source of heterogeneity may mainly come from the differences of the study population, on the one hand, the population inclusion criteria are different, the other studies include the full degree of COPD, while the COPD, of the item is only included in the COPD, of the 


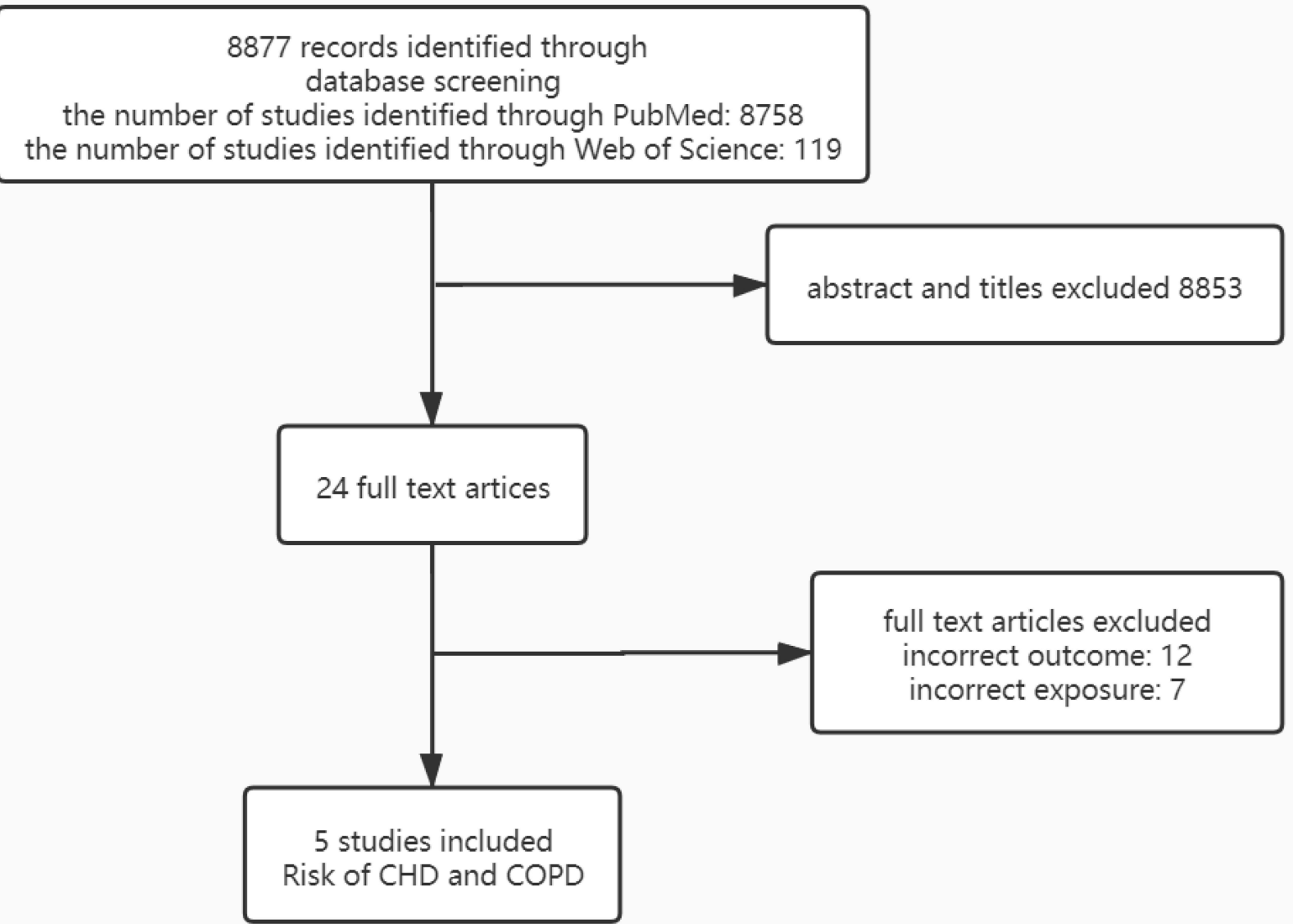

Figure I The inclusion and exclusion data process summarization. Data sources were all PubMed and web of science searched up to August 202I based on specific search term.

stage $1+2$, on the other hand, the sample size in the item is too large, which leads to greater heterogeneity. As a result, Ingebrigtsen stage 1+2 2020 was removed.

The combined analysis results of this study show that COPD patients have a higher risk of CHD, and COPD is a risk factor for $\mathrm{CHD}$, which is consistent with the current research on the mechanism of CHD. Though the mechanisms by which COPD increases CHD risk are not clear, patients with COPD often display abnormally high concentrations of circulating systemic inflammatory could be the main reason, ${ }^{3-6}$ and the lung hyperinflation also represent one of the most important problem related to the high thoracic pressure that could be generated. ${ }^{14}$ However, public or health professionals and patients with COPD still generally have insufficient understanding of "COPD increases the risk of developing CHD," leading to poor prevention of coronary heart disease. The exact cause is unclear, but the lack of specific guidelines for COPD as a risk factor for $\mathrm{CHD}$ and the management of coronary heart disease and cardiovascular risk factors in COPD patients may be an important contributing factor.

In addition, clinical studies proved that antiinflammatory treatment and the bronchodilators lower the incidence of cardiovascular events. ${ }^{14-16}$ Therefore, the therapies of directly or indirectly modulating chronic inflammation and the bronchodilators is an important approach for prevention of CHD and treatment of COPD. The development of reasonable exercise and nutritional interventions for pulmonary rehabilitation is also an important therapeutic measure. Studies have shown that reasonable lung rehabilitation can reduce cardiovascular risk factors and help to improve prognosis. ${ }^{17}$

The main limitation of our research is that, most articles are adjusted for age, sex, co-illness or confounding factors to get the final HR value, but Liao WC 2015 only adjusts the basic age and sex. ${ }^{13}$ And most of the articles did not grade COPD except Ingebrigtsen 2020. I hope that there will be more cohort research in the future research. 


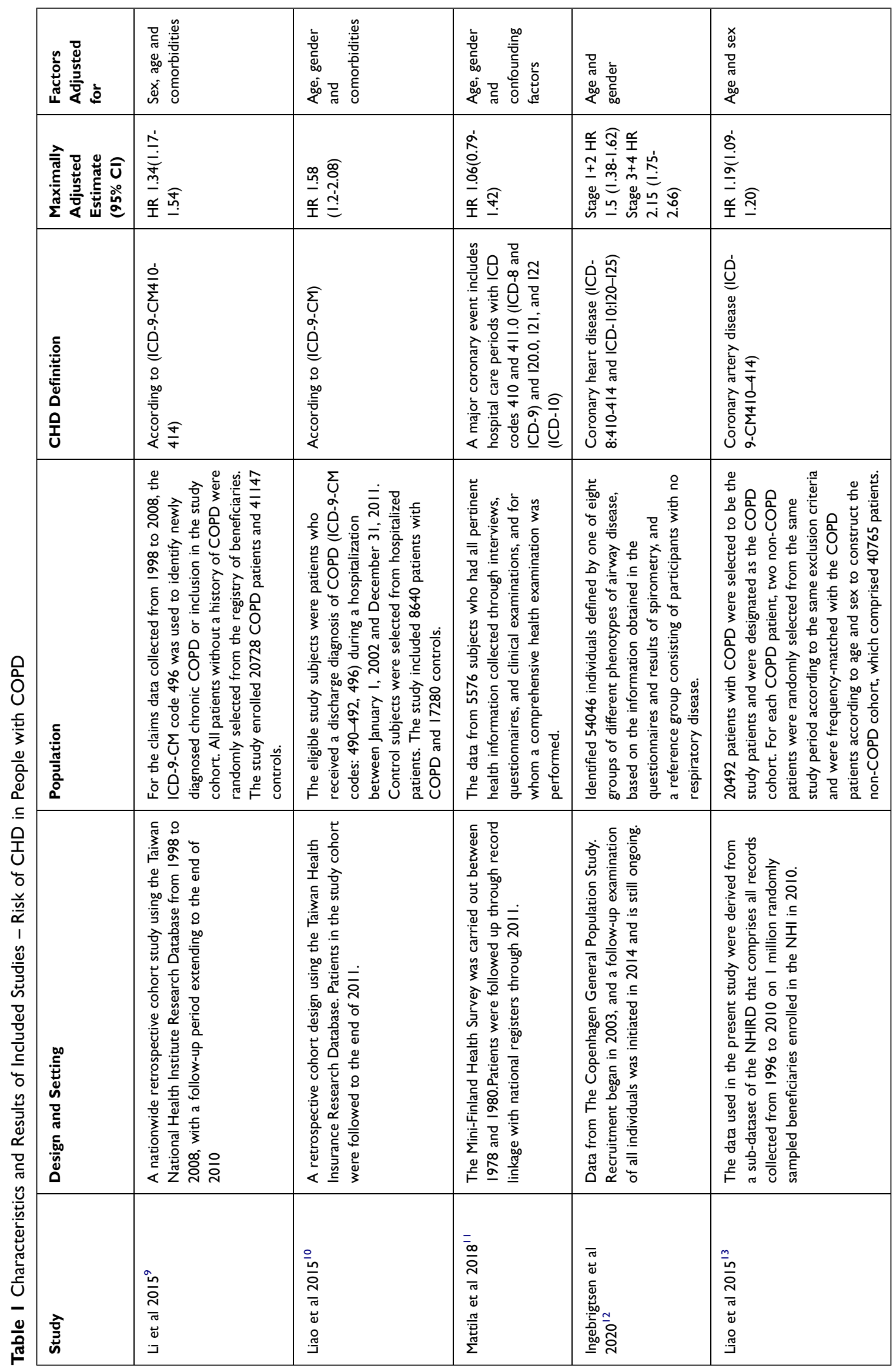




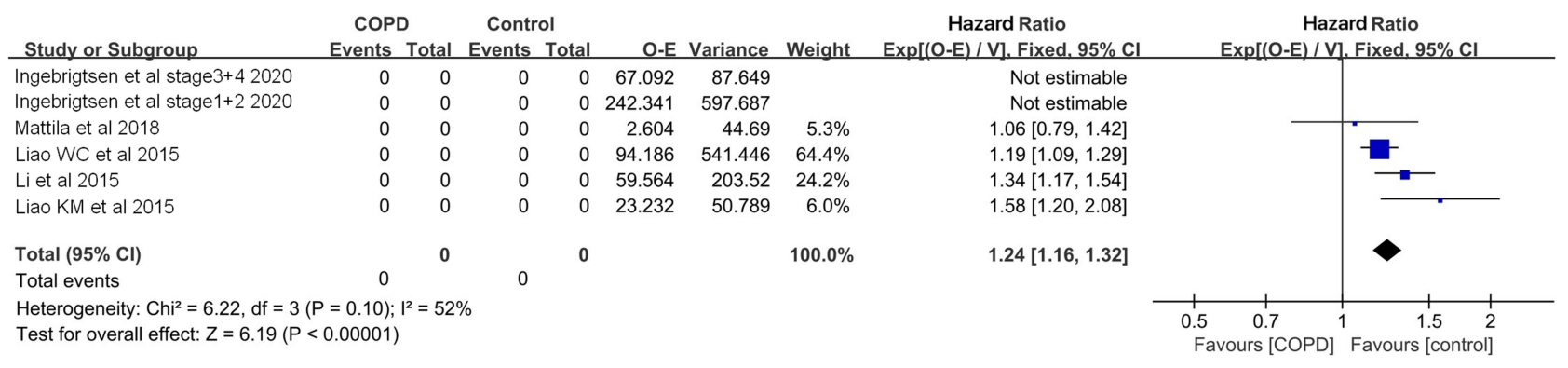

Figure 2 Forest plot shows risk of CHD in people with COPD. It showed that the risk of CHD in COPD patients was I.24 times higher than that in non-COPD patients. Abbreviations: COPD, chronic obstructive pulmonary disease; $\mathrm{CHD}$, coronary heart disease.

Because it has a stronger causal relationship than casecontrol studies, and it is clearer about the relationship between risk factors and disease.

\section{Conclusion}

The findings suggest that patients with COPD are at a higher risk of developing CHD than non-COPD patients.

\section{Abbreviations}

CHD, coronary heart disease; COPD, chronic obstructive pulmonary disease.

\section{Data Sharing Statement}

This is a meta-analysis of previously published studies.

\section{Ethics Approval}

The present meta-analysis was not required for the ethics approval in our institute, because none of patients of our institute were included.

\section{Patient and Public Involvement}

No patient involved.

\section{Funding}

There is no funding to report.

\section{Disclosure}

The author reports no conflicts of interest in this work.

\section{References}

1. King PT. Inflammation in chronic obstructive pulmonary disease and its role in cardiovascular disease and lung cancer. Clin Transl Med. 2015;4(1):68. doi:10.1186/s40169-015-0068-z

2. Almagro P, Boixeda R, Diez-Manglano J, Gómez-Antúnez M, LópezGarcía F, Recio J. Insights into chronic obstructive pulmonary disease as critical risk factor for cardiovascular disease. Int J Chron Obstruct Pulmon Dis. 2020;15:755-764. doi:10.2147/COPD.S238214
3. Hillas G, Perlikos F, Tsiligianni I, Tzanakis N. Managing comorbidities in COPD. Int J Chron Obstruct Pulmon Dis. 2015;10:95-109.

4. Kunisaki KM, Dransfield MT, Anderson JA, et al. Exacerbations of chronic obstructive pulmonary disease and cardiac events. A post hoc cohort analysis from the SUMMIT randomized clinical trial. Am J Respir Crit Care Med. 2018;198(1):51-57. doi:10.1164/rccm.201711-2239OC

5. Putcha N, Drummond MB, Wise RA, Hansel NN. Comorbidities and chronic obstructive pulmonary disease: prevalence, influence on outcomes, and management. Semin Respir Crit Care Med. 2015;36 (4):575-591. doi:10.1055/s-0035-1556063

6. Aisanov Z, Khaltaev N. Management of cardiovascular comorbidities in chronic obstructive pulmonary disease patients. $J$ Thorac Dis. 2020;12(5):2791-2802. doi:10.21037/jtd.2020.03.60

7. Crisan L, Wong N, Sin DD, Lee HM. Karma of cardiovascular disease risk factors for prevention and management of major cardiovascular events in the context of acute exacerbations of chronic obstructive pulmonary disease. Front Cardiovasc Med. 2019;6:79. doi:10.3389/fcvm.2019.00079

8. Piepoli MF, Hoes AW, Agewall S, et al. 2016 European guidelines on cardiovascular disease prevention in clinical practice. The sixth joint task force of the European society of cardiology and other societies on cardiovascular disease prevention in clinical practice (constituted by representatives of 10 societies and by invited experts. developed with the special contribution of the European association for cardiovascular prevention \& rehabilitation]. G Ital Cardiol. 2017;18(7):547-612.

9. $\mathrm{Li} \mathrm{CH}$, Chen WC, Liao WC, et al. The association between chronic obstructive pulmonary disease and Parkinson's disease: a Nationwide Population-Based Retrospective Cohort Study. Qjm an Int J Med. 2015;108(1):39-45. doi:10.1093/qjmed/hcu136

10. Liao KM, Ho CH, Ko SC, Li CY. Increased risk of dementia in patients with chronic obstructive pulmonary disease. Medicine. 2015;94(23):e930. doi:10.1097/MD.0000000000000930

11. Mattila T, Vasankari T, Rissanen H, Knekt P, Puukka P, Heliovaara M. Airway obstruction and the risk of myocardial infarction and death from coronary heart disease: a national health examination survey with a 33-year follow-up period. Eur J Epidemiol. 2018;33(1):89-98. doi:10.1007/s10654-017-0278-3

12. Ingebrigtsen TS, Marott JL, Vestbo J, Nordestgaard BG, Lange P. Coronary heart disease and heart failure in asthma, COPD and asthma-COPD overlap. BMJ Open Respir Res. 2020;7(1):e000470. doi:10.1136/bmjresp-2019-000470

13. Liao WC, Lin CL, Chang SN, Tu CY, Kao CH. The association between chronic obstructive pulmonary disease and dementia: a Population-Based Retrospective Cohort Study. Eur J Neurol. 2015;22(2):334-340. doi:10.1111/ene.12573

14. Santus P, Radovanovic D, Di Marco S, et al. Effect of indacaterol on lung deflation improves cardiac performance in hyperinflated COPD patients: an interventional, randomized, double-blind clinical trial. Int J Chron Obstruct Pulmon Dis. 2015;10:1917-1923. doi:10.21 47/COPD.S91684 
15. Wang $Y$, Liu $X$, Shi $H$, et al. NLRP3 inflammasome, an immune-inflammatory target in pathogenesis and treatment of cardiovascular diseases. Clin Transl Med. 2020;10(1):91-106. doi:10.1002/ctm2.13

16. Santus P, Centanni S, Verga M, Di Marco F, Matera MG, Cazzola M. Comparison of the acute effect of tiotropium versus a combination therapy with single inhaler budesonide/formoterol on the degree of resting pulmonary hyperinflation. Respir Med. 2006;100 (7):1277-1281. doi:10.1016/j.rmed.2005.10.008
17. Gale NS, Duckers JM, Enright S, Cockcroft JR, Shale DJ, Bolton CE. Does pulmonary rehabilitation address cardiovascular risk factors in patients with COPD? BMC Pulm Med. 2011;11(1):20. doi:10.1186/ $1471-2466-11-20$

\section{Publish your work in this journal}

The International Journal of COPD is an international, peer-reviewed journal of therapeutics and pharmacology focusing on concise rapid reporting of clinical studies and reviews in COPD. Special focus is given to the pathophysiological processes underlying the disease, intervention programs, patient focused education, and self management protocols. This journal is indexed on PubMed Central, MedLine and CAS. The manuscript management system is completely online and includes a very quick and fair peer-review system, which is all easy to use. Visit http://www.dovepress.com/testimonials.php to read real quotes from published authors. 